\title{
Determination of Modal Parameters for Finned Heat Exchanger Tubes of Various Configurations
}

\author{
Sandeep R. Desai*, S Pavitran \\ Vishwakarma Institute of Technology, Pune, Maharashtra, India \\ *Corresponding Author: san_skh@rediffmail.com
}

Copyright $(2013$ Horizon Research Publishing All rights reserved.

\begin{abstract}
Very first step in the analysis of fluid elastic vibrations of heat exchanger tubes is determination of modal parameters (natural frequency and damping ratios) of the tubes. Natural frequencies and damping ratios of the tubes are very important parameters as critical velocity at instability also depends on them. Lower natural frequencies are desired so as to achieve the fluid elastic instability with limited flow capacities of the pump. This paper presents part of the research work to analyze fluid elastic vibrations of finned tubes subjected to single and two phase cross flows of water and air-water. It consists of determination of modal parameters of finned tubes for two different fin pitches $(2.54$ and $6.35 \mathrm{~mm}$ ). The work also consists of determination of modal parameters for finned tube attached with welded rods of $220 \mathrm{~mm}$ length to reduce natural frequencies. It helps to know how fin tube parameters affect the natural frequency and damping values and hence their proneness to fluid elastic vibration. Further, as a requisite for easy conduct of experiments on fluid elastic vibration analysis of finned tubes, it is found that, natural frequencies of 56 and $65 \mathrm{~Hz}$ of fin tubes are reduced to 14 and $17 \mathrm{~Hz}$ respectively when solid rods of $220 \mathrm{~mm}$ length are welded to them.
\end{abstract}

Keywords Natural frequencies, damping ratios, finned tubes, solid rods

\section{Introduction}

Flow induced vibrations always has been a cause of concern for failure of tubes in shell and tube heat exchangers as it causes damage to tubes by various excitation mechanisms such as fluid elastic instability, vortex shedding, acoustic resonance, turbulent buffeting and jet switching [1]. Out of these, fluid elastic instability is the dominant mechanism as far as tube arrays in shell and tube heat exchangers subjected to cross flow are concerned. Majority of the work that has been carried out on flow induced vibration analysis includes vibration analysis of plain tube arrays subjected to single and two-phase cross flow of Water, Air-Water and Refrigerants (R11, R22, R134a etc.)
[2],[3],[4]. These days finned tubes instead of plain tubes are used in most of the heat exchangers and their use is likely to increase more in coming days. Most recent heat exchangers have started using finned tubes to increase heat transfer efficiency and to reduce sizes of the heat exchangers. This has led to a need to analyze effect of fins on flow induced vibration characteristics of heat exchanger tubes. In the recent past, researchers have started carrying out the work on fluid elastic vibration analysis of finned tube arrays subjected to air cross flow and have analyzed the effect of type of tube array and fin density on fluid elastic instability threshold[5], [6].

Analysis of flow induced vibrations in general or fluid elastic instability in specific requires the simulation of these fluid elastic vibrations and then analyzing the effect of related parameters on the threshold of critical velocity at which fluid elastic instability occurs. There are several structural and fluid parameters that are required to be taken care so as to develop an experimental setup to simulate fluid elastic vibrations. Some of these are; fluid velocity (Pump capacity), modal parameters of the structure, geometry of the structure, boundary conditions, size and cost of the setup etc. which are all interrelated. There are various other parameters that have an effect on vibration behavior of finned tubes, such as fin height, fin sizes, tube array pitch, fin type, fin material etc.

In order to analyze fluid elastic vibrations of finned tube arrays, modal parameters of these tubes need to be known. Since vibration analysis of plain tubes was the focus till the recent past, when research on finned tube arrays is started, there is not literature available that highlights effect of fin parameters on modal parameters of the tubes, Though these modal parameters were determined experimentally and compared with theoretical results, effect of fin tube parameters was not addressed [7]. The present work aims at providing information on determination of modal parameters (natural frequencies and damping ratios) of finned tubes with two different fin pitches $(2,54$ and $6.35 \mathrm{~mm})$ and to understand the parameters that contribute in deciding the natural frequencies and damping ratios of fin tubes used in heat exchanger applications. Another part of the work includes determination of modal parameters of finned tubes 
welded with rods of certain length to determine the reduction in natural frequency essential to achieve fluid elastic instability with lower flow capacity of the pump for fluid elastic vibration experiments on finned tubes.

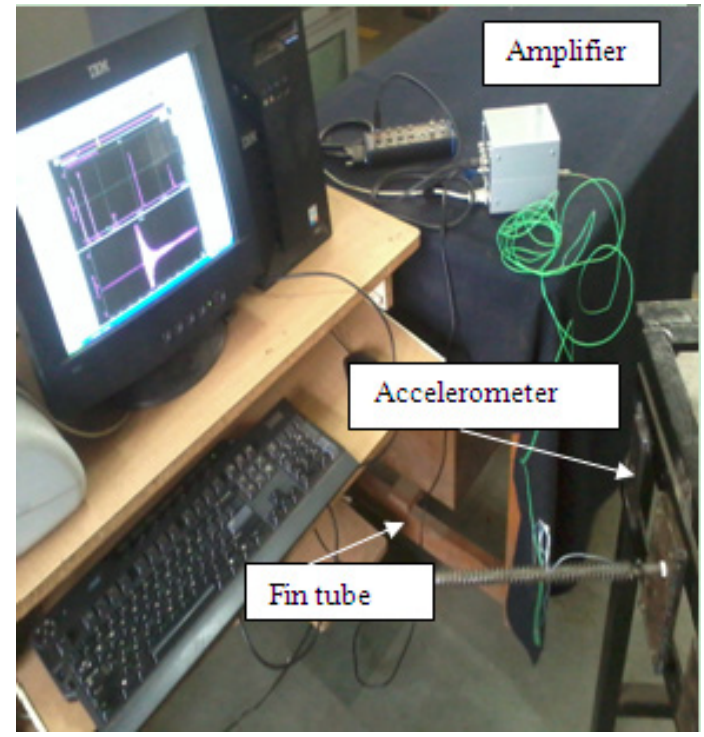

Figure 1. Experimental Setup for free vibration testing-Finned tube

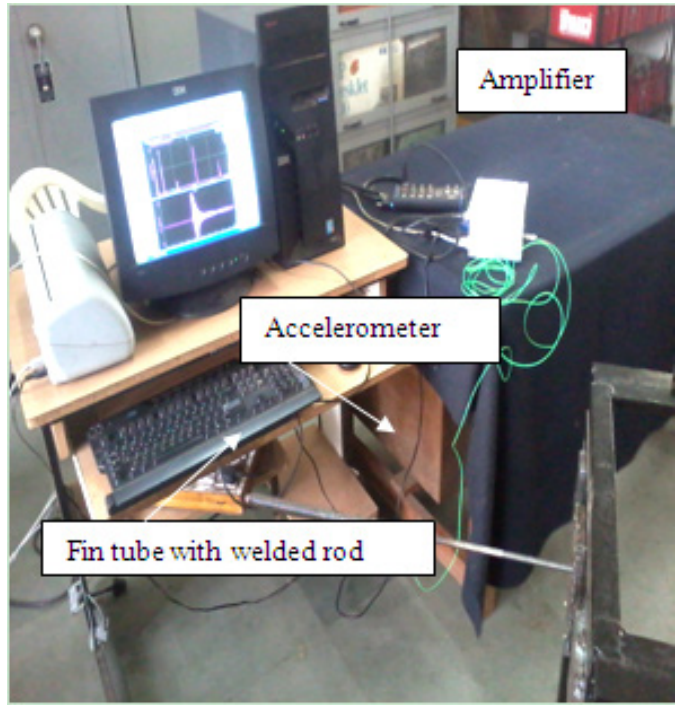

Figure 2. Experimental Setup for free vibration testing - Finned tube with rod.

\section{Experimental Setup}

Experimental free vibration analysis for fin tubes with two different fin pitches $(2.54$ and $6.35 \mathrm{~mm}$ ) and fin tubes that are welded with a rods to reduce their natural frequencies is carried out using data acquisition system (Dew soft 7.0.5) along with a miniature accelerometer (Kistler 8778A500) and a signal conditioner. The experimental setup for free vibration analysis of fin tubes and fin tubes with solid rods welded is shown in fig. 1 and fig. 2 respectively. Miniature accelerometer that has low weight (5 grams) and small size is used to minimize difficulties encountered in mounting it on cylindrical surface of the tubes. Further, low weight has helped in producing the results accurately. An impact was given on each of the fin tube geometries one by one to obtain frequency domain plots as shown in fig. 3, fig.4, fig.5 and fig.6. The specifications of fin tubes are given in Table 1 below.

Table 1. Fin Tube Specifications

\begin{tabular}{|c|c|}
\hline Legend & Specifications \\
\hline Tube O.D. and I.D. & 12.70 and $9.30 \mathrm{~mm}$ \\
\hline Tube Material & Stainless Steel 304 \\
\hline Length of the tubes & $355 \mathrm{~mm}$ \\
\hline Length of solid rod & $220 \mathrm{~mm}$ \\
\hline Type of tubes & Finned type \\
\hline Type of fin & Spiral crimped type \\
\hline Fin thickness & $0.5 \mathrm{~mm}$ \\
\hline Fin height & $5 \mathrm{~mm}$ \\
\hline Fin Pitch & 2.54 and $6.35 \mathrm{~mm}$ \\
\hline Legend & Specifications \\
\hline Tube O.D. and I.D. & 12.70 and $9.30 \mathrm{~mm}$ \\
\hline Tube Material & Stainless Steel 304 \\
\hline Length of the tubes & $355 \mathrm{~mm}$ \\
\hline Length of solid rod & $220 \mathrm{~mm}$ \\
\hline Type of tubes & Finned type \\
\hline Type of fin & Spiral crimped type \\
\hline Fin thickness & $0.5 \mathrm{~mm}$ \\
\hline Fin height & $5 \mathrm{~mm}$ \\
\hline Fin Pitch & 2.54 and $6.35 \mathrm{~mm}$ \\
\hline
\end{tabular}

\section{Results and Discussion}

\subsection{Measurement of Natural Frequencies}

Natural frequencies are noted from frequency domain plots as shown in figures 3, 4, 5 and 6 and are listed in Table 2 for various fin tube geometries.

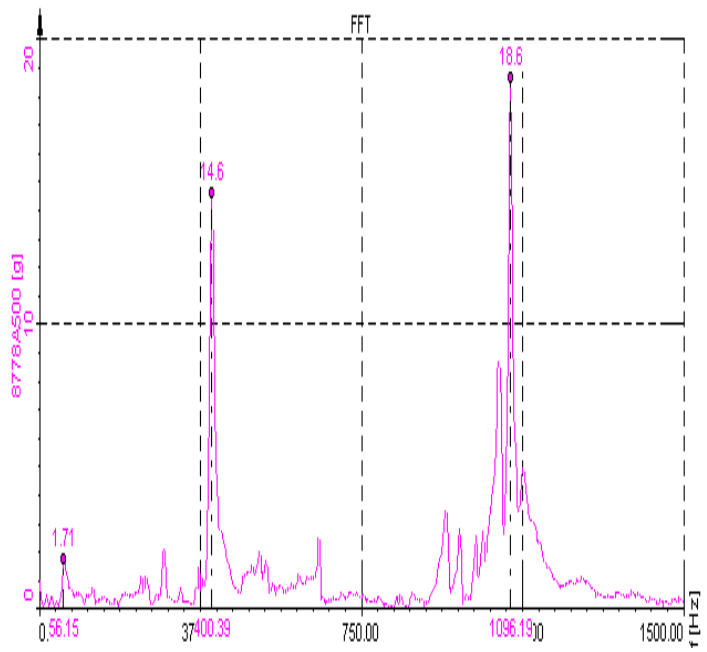

Figure 3. Natural frequencies of a fin tube ( $P i t c h=2.54 \mathrm{~mm}$ ) 


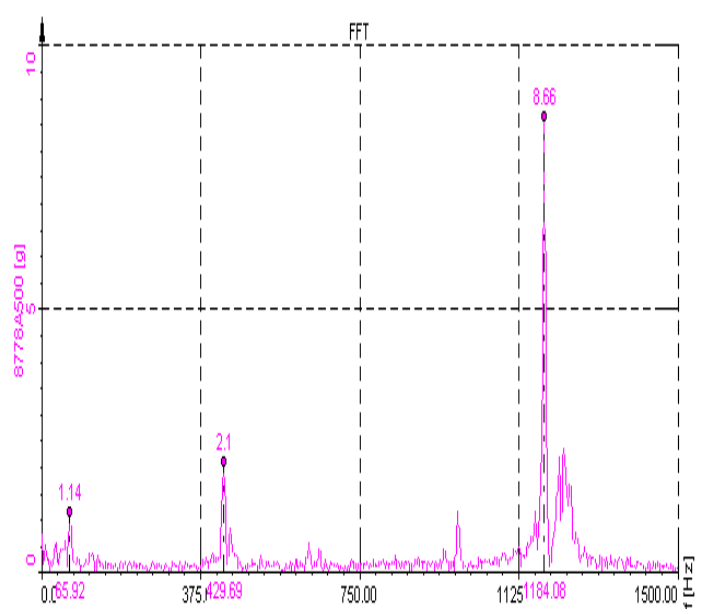

Figure 4. Natural frequencies of a fin tube ( Pitch=6.35 mm)

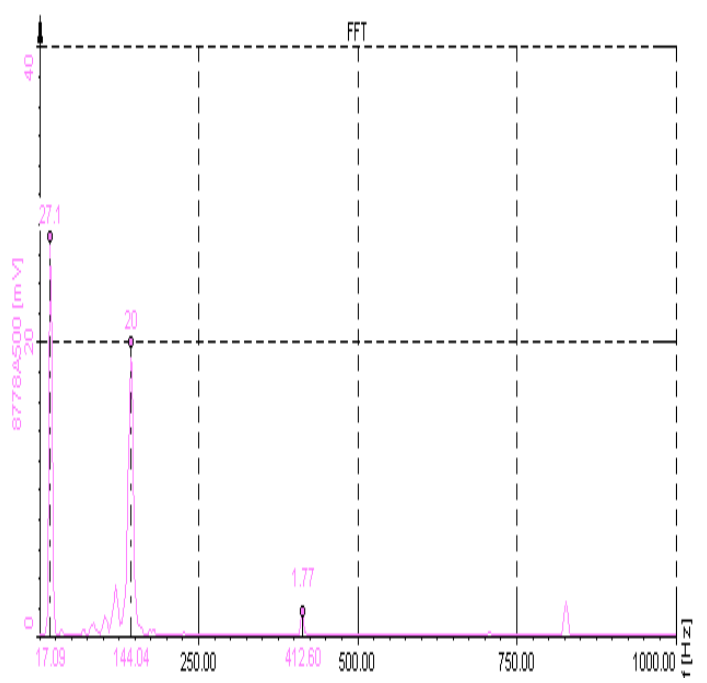

Figure 5. Natural frequencies of a fin tube with $\operatorname{rod}(\mathrm{Pitch}=2.54 \mathrm{~mm})$

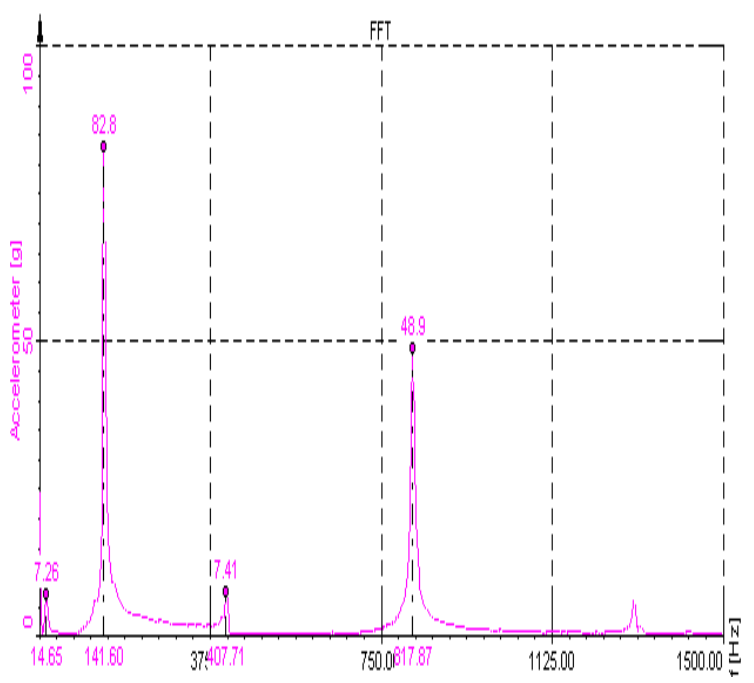

Figure 6. Natural frequencies of a fin tube with $\operatorname{rod}(\mathrm{Pitch}=6.35 \mathrm{~mm})$

\subsection{Measurement of Damping}

Measurement of damping of fin tubes is also significant as it is also the parameter on which critical velocity at fluid elastic instability threshold depends. There are two methods to determine damping of such structures;

i) Logarithmic decrement method: It determines logarithmic decrement $\boldsymbol{\delta}$ from time domain plots.

ii) Half power bandwidth method: It determines damping ratio $\zeta$ from frequency domain plots.

In this work, half power bandwidth method as shown in fig. 7 is used to determine $\zeta$ and then $\delta$.

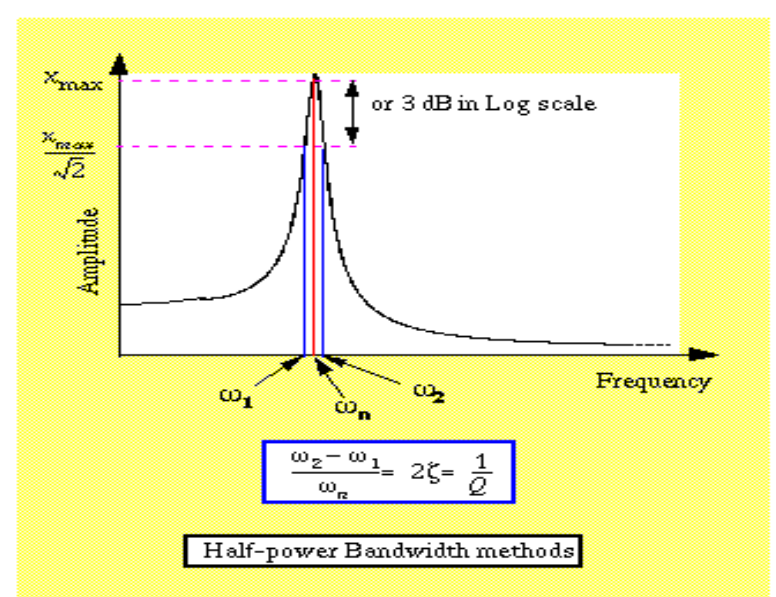

Figure 7. Half Power Banwidth method to determine damping ratio.

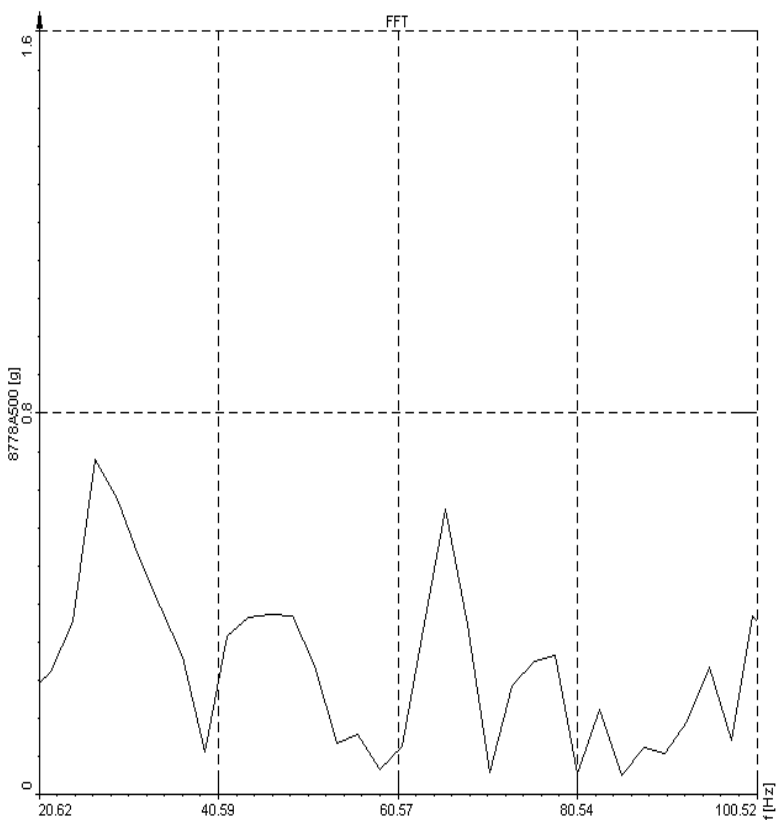

Figure 8. Peak showing first natural frequency for finned tube $(p=6.35$ $\mathrm{mm})$

In this method, FRF amplitude of the system is obtained first. Corresponding to each natural frequency, there is a peak in FRF amplitude. $3 \mathrm{~dB}$ down from the peak (or 0.707 of the peak amplitude) there are two points called as half power points. Such half power points are located in each of the peaks shown in figures 8,9,10 and 11 below and damping ratios are calculated. 
As shown in fig. 9, damping ratio for finned tube with fin pitch $\mathrm{p}=2.54 \mathrm{~mm}$ is calculated as;

$$
\begin{array}{ccc}
\zeta=\frac{\Delta f n}{2 x f n} \quad \ldots \ldots . & 1 \\
\zeta=\frac{59.97-56.57}{2 x 58.59}=\frac{3.4006}{117.18} & \ldots \ldots \ldots & 2
\end{array}
$$

Damping ratio, $\zeta=0.02902$

Therefore, Logarithmic decrement,

$$
\delta=2 \times \pi \times \zeta=0.1823
$$

Similarly, from figures 8,10 and $11, \zeta$ and $\delta$ are calculated for various fin geometries and are summarized in Table 2 .

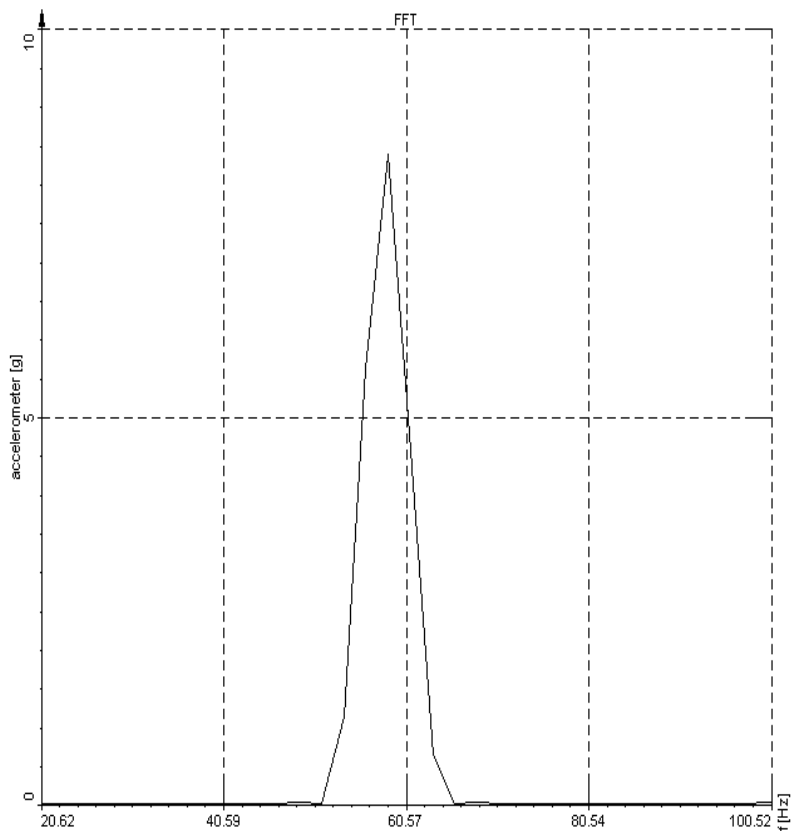

Figure 9. Peak showing first natural frequency for finned tube $(p=2.54$ $\mathrm{mm})$

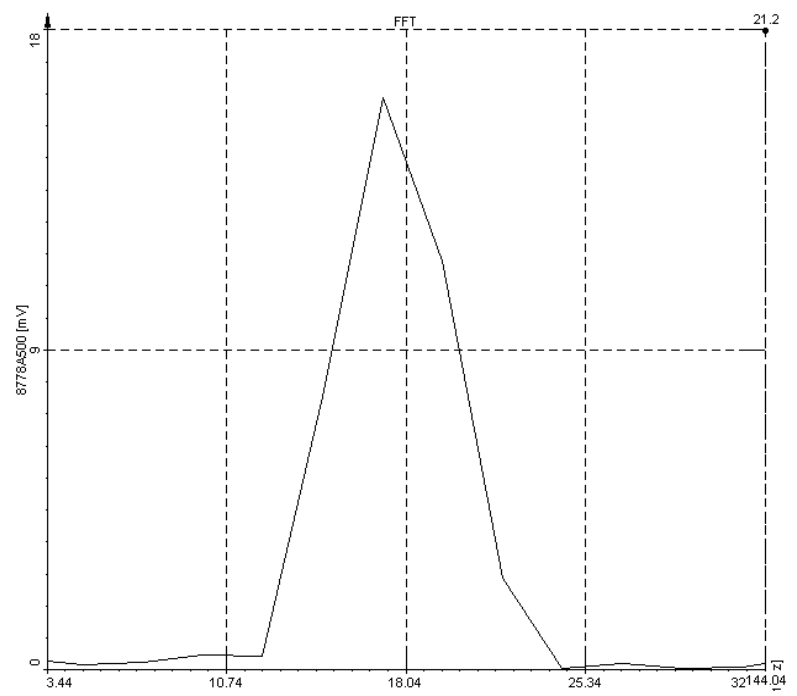

Figure 10. Peak showing first natural frequency for a finned tube with rod $(\mathrm{p}=6.35 \mathrm{~mm})$

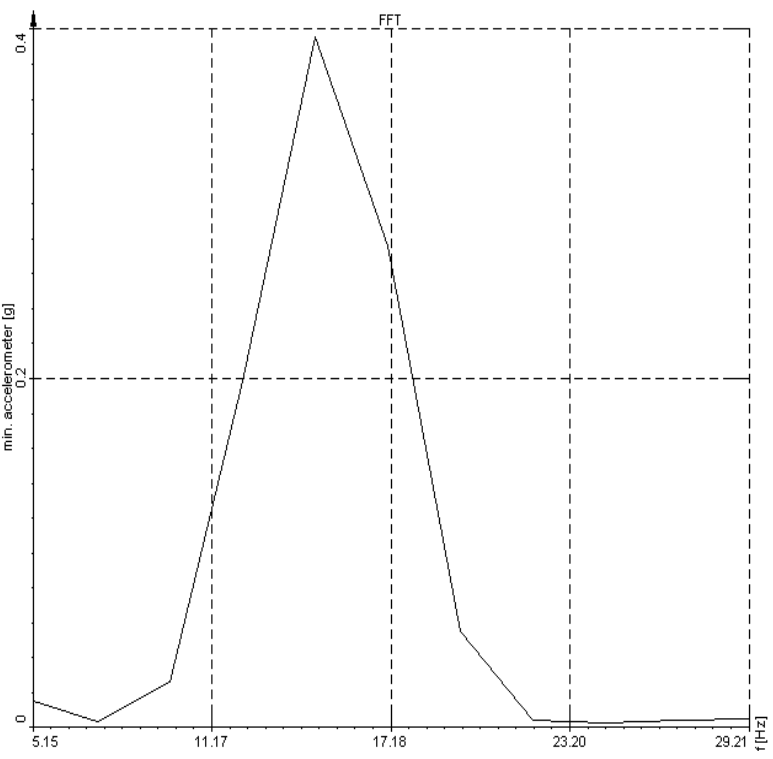

Figure 11. Peak showing first natural frequency for a finned tube with rod $(\mathrm{p}=2.54 \mathrm{~mm})$

Table 2 lists and compares modal parameters (i.e. natural frequencies and damping ratios) for different fin tube geometries. Two fin tubes each with a different fin pitch $(2.54$ and $6.35 \mathrm{~mm})$ are tested for modal parameters and it is observed that natural frequencies for fin tubes with lower fin pitch $(2.54 \mathrm{~mm})$ are lower compared to the one with higher fin pitch $(6.35 \mathrm{~mm})$. This happens because of the higher fin densities of earlier fin tube compared to later one where fin density is higher due to higher fin pitch. The reason for the same is also higher tube mass for fin tube with $2.54 \mathrm{~mm}$ pitch compared to fin tube with $6.35 \mathrm{~mm}$ pitch. When fin tubes are welded with solid rods of $220 \mathrm{~mm}$ length, first natural frequency is reduced from $66 \mathrm{~Hz}$ to $17 \mathrm{~Hz}$ for a fin tube with higher pitch $(6.35 \mathrm{~mm})$ and from $56 \mathrm{HZ}$ to $15 \mathrm{~Hz}$ for a fin tube with lower fin pitch $(2.54 \mathrm{~mm})$. The natural frequencies are reduced drastically because of; increased length of the fin tube geometries by welding solid rods to them and due to increased mass of the fin tube-rod geometry.

When results for damping ratios are compared, it is observed that, damping ratio increases with increased fin density or with decreased fin pitch (p). This also holds good for fin tubes when they are welded with solid rods. It is also observed that damping ratios of fin tubes welded with solid rods are higher compared to mere fin tube geometries.

Fluid elastic instability threshold is directly proportional to natural frequency and logarithmic decrement and natural frequency among these is more dominenent to decide this threshold. So, reducing natural frequencies of fin tubes by welding solid rod to them makes it possible to simulate fluid elastic vibrations with lower flow capacities of the pump. Therefore, for fluid elastic vibration experiments under consideration, fin tubes welded with solid rods as tested above could be used effectively. 
Table 2. Comparison of results for different fin tube geometries

\begin{tabular}{|c|c|c|c|c|c|}
\hline \multirow{2}{*}{$\begin{array}{c}\text { Fin Tube } \\
\text { geometry }\end{array}$} & \multicolumn{3}{|c|}{$\begin{array}{c}\text { Natural frequency (fn) in } \\
\text { Hz }\end{array}$} & \multirow{2}{*}{$\delta$} & $\zeta$ \\
\cline { 2 - 5 } & $\begin{array}{c}\text { Mode } \\
1\end{array}$ & $\begin{array}{c}\text { Mode } \\
2\end{array}$ & $\begin{array}{c}\text { Mode } \\
3\end{array}$ & & \\
\hline $\begin{array}{c}\text { Fin tube } \\
(\mathrm{p}=6.35 \mathrm{~mm})\end{array}$ & 65.92 & 429 & 1184 & 0.1615 & 0.026 \\
\hline $\begin{array}{c}\text { Fin Tube } \\
(\mathrm{p}=2.54 \mathrm{~mm})\end{array}$ & 56.15 & 400 & 1096 & 0.1823 & 0.029 \\
\hline $\begin{array}{c}\text { Fin tube with } \\
\text { rod(p=6.35 mm })\end{array}$ & 17.09 & 144 & 412 & 0.7246 & 0.1153 \\
\hline $\begin{array}{c}\text { Fin tube with } \\
\text { rod (p=2.54 mm) } \\
(\mathrm{p}=2.54 \mathrm{~mm})\end{array}$ & 14.65 & 141 & 407 & 0.8448 & 0.1344 \\
\hline
\end{tabular}

\section{Conclusions}

One of the important steps in fluid elastic vibration analysis of heat exchanger tube arrays is to determine modal parameters i.e. natural frequencies and damping ratios of the tubes. Objective of the present work therefore was to determine these modal parameters for various fin tube geometries used in heat exchanger applications and to understand the parameters that contribute in deciding the natural frequencies and damping ratios. Fin tubes with two different fin pitches $(2.54$ and $6.35 \mathrm{~mm})$ are tested experimentally for their modal parameters. The conclusions are summarized as given below;

- Natural frequencies of fin tubes depends upon fin pitch and hence fin density along with geometrical dimensions (i.e. length and diameter of the tubes), material properties (i.e. density and modulus of elasticity) and tube boundary conditions (i.e. cantilever or simply supported).

- Natural frequencies of fin tubes compared to plain tubes are less because of fins and their additional mass and therefore fin tubes are more prone to vibrations than plain tubes.

- More the fin density or lower the fin pitch, lower are the natural frequencies. As the fin pitch decreases, it reduces natural frequencies due to increased fin density and higher fin tube mass.

- Damping ratios and Logarithmic decrements are higher for fin tubes with lower fin pitch i.e. fin pitch $2.54 \mathrm{~mm}$. This holds good both for fin tubes and fin tubes welded with solid rods.

- Natural frequencies are reduced and damping ratios are increased for fin tubes when they are welded with solid rods.

- Experiments for fluid elastic vibration analysis require lower values of modal parameters to simulate instability in tubes with lower flow rates of the pumps. For the ongoing experiments on fluid elastic vibration analysis of finned tubes subjected to cross flow of water, this has been made possible as natural frequencies of fin tubes of different fin pitches are reduced to $17 \mathrm{~Hz}$ and $14 \mathrm{~Hz}$ from $66 \mathrm{~Hz}$ and 56 $\mathrm{Hz}$ respectively by welding solid rods of $220 \mathrm{~mm}$ in length.

\section{Acknowledgements}

The authors gratefully acknowledge the financial assistance for experimentation on fluid elastic vibrations provided by A.I.C.T.E., New Delhi under Research Promotion Scheme (R.P.S.). The authors also express their sincere thanks to undergraduate and postgraduate students for their valuable contributions.

\section{REFERENCES}

[1] Robert D. Blevins, Flow-induced Vibrations, Van Nostrand Reinhold Company, 1977.

[2] G. Ricciardi, M.J. Pettigrew and N.W. Mureithi, Fluidelastic Instability in a Normal Triangular Tube Bundle Subjected to Air-Water Cross-Flow, Journal of Pressure Vessel Technology, 133, 061301-1- 061301-9, 2011

[3] D. Mitra, V.K.Dhir, I. Catton, Fluid-elastic instability in tube arrays subjected to air-water and steam-water cross-flow, Journal of fluids and structures, 25, 1213-1235, 2009

[4] M.J.Pettigrew, C.E. Taylor and B.S. Kim, The Effects of Bundle Geometry on Heat Exchanger Tube Vibration in Two-Phase Cross Flow, Journal of Pressure Vessel Technology ,123, 414-420, 2001

[5] J. Wang, D.S.Weaver, "Fluid elastic Instability in Normal and parallel Triangular Arrays of Finned Tubes, "Journal of Pressure Vessel Technology, 134, pp. 1-7, 2012.

[6] R.H.Lumsden, D.S. Weaver , "The Effect of Fins on Fluidelastic Instability in In-Line and Rotated Square Tube Arrays, "Journal of Pressure Vessel Technology, 132, pp. $1-6,2010$.

[7] U Bolleter and R.D. Blevins, "Natural Frequencies of finned heat exchanger tubes", Journal of sound and vibration, 80, 367-371, 1982. 